\title{
Institutional Commitment Section of Cancer Center Support Grant Application
}

National Cancer Institute

\section{Source}

National Cancer Institute. Institutional Commitment Section of Cancer Center Support

Grant Application. NCI Thesaurus. Code C39430.

The Institutional Commitment section of the Cancer Center Support Grant Application includes a schematic description of the Cancer Center's position within the institution(s) in relation to other organizational components (e.g., schools, departments, institutes, or the equivalent). 